\title{
Design of Kid Toy Packaging: A Questionnaire Study
}

\author{
Shijian CANG, Pingping LI, Hanqing REN \& Guifang JIN \\ Department of Product Design, Tianjin University of Science and Technology, Tianjin 300457, China
}

\begin{abstract}
For the kid toys, the purchasers and the users are different persons; the purchasers are often the parents and the users are the children. To get an optimal kid toy package, it is necessary to analyze the correlation between the kid toy packaging and purchasing behavior. The questionnaires are used to get the preference distribution of kid toy packaging elements in this paper. The statistical results show that the preference to the packaging elements of the children and the parents are similar to each other although there are some differences in details, which were shown by a case study. Through the preference test of the kid toy packaging, the principals to choose the kid toy packaging elements were proposed, which can help to achieve optimal design for kid toy packages.
\end{abstract}

KEYWORDS: Kid toy packaging; Optimal design; Visual perception; Social cognition

\section{INTRODUCTION}

Like other consumer products on the market, kid toys should also go through several steps, such as concept design, assessment test, user experience, producing, packaging, marketing and so forth, before all sorts of toys can reach the hands of children. In these steps, the packaging is often ignored since the packaging is not the main part of the product. However, the packages not only protect toys, it can also induce consumers to buy (Liu \& Yang 2011). For other products, the buyer act as the user and the objective of packaging is clear; and its packaging design can be determined by the buyers' habits, psychological motivation, aesthetic taste, etc. For the kid toys, the purchasers and the users are different persons; the purchasers are often the parents and the users are the children (Tiwasing \& Sahachaisaeree 2010, 2012), which makes the kid toy packaging be different from the packaging of other goods or products.

Parents usually choose toys according to color, texture, shape, materials, function, safety, etc. In the absence of physical contact with the toys, parents will first check the toy package. The parents will not buy the toy if the toy packaging cannot meet their expectations. Children often choose toys according to their visual perception (Flavell 1981), and the information of visual perception is mainly from the package. Hence, the children will not be interested in the toys if the toy packages do not attract the children. Because of the differences between the cognition of parents and the physiological perception of children (Flavell 1999, Epstein 1998), the preferences of the parents and children to the kid toy packages are different. Therefore, the kid toy packaging design is a complex problem since it is not easy to find the equilibrium of the cognition of parents and the physiological perception of children.

The aim of this research is to obtain the principles of selecting the kid toy packaging design elements, which can be used to optimize the kid toy packaging design, based on the empirical analysis and the statistic preference tests of parents and children for the kid toy packaging elements.

\section{CONCEPTUAL MODEL}

To ensure the rationality of choosing the kid toy packaging elements, it is necessary to analyze the relationship between the toy package and the purchasing behavior in theory. The theoretical basis for bridging the kid toy packaging and purchasing behavior can be mainly reflected in the following three principles:

The first is the Principle of Gestalt psychology. This principle not only emphasizes the integrity of things, but also considers the detachability of various elements. The package is not only depending on a single element; and it is made by combining several elements. Here the Gestalt psychology 
theories can be used to explain the impacts of packaging elements on the children's physiological perception, which can help realize an optimal packaging design (Muth \& Carbon 2013).

The second is the Principle of selling psychology. In the process of buying and selling, parents pay attention to the intrinsic value and function. It is important to investigate how the package can make the parents feel the toy can meet their requirements (Tracy 2005).

The last is the aesthetic principles. The aesthetic principles can guide how to choose the toy packaging elements such as colors, textures, patterns and text, and so on (Budd 1999).

Based on the above-mentioned principles, a new conceptual model of kid toy packaging and purchasing behavior can be obtained and it is shown in Fig.1. As can be seen from Fig.1, the realization of purchasing behavior depends on whether the packaging meets the cognitive psychology which is determined by the social cognition of parents and the physiological perception of children.

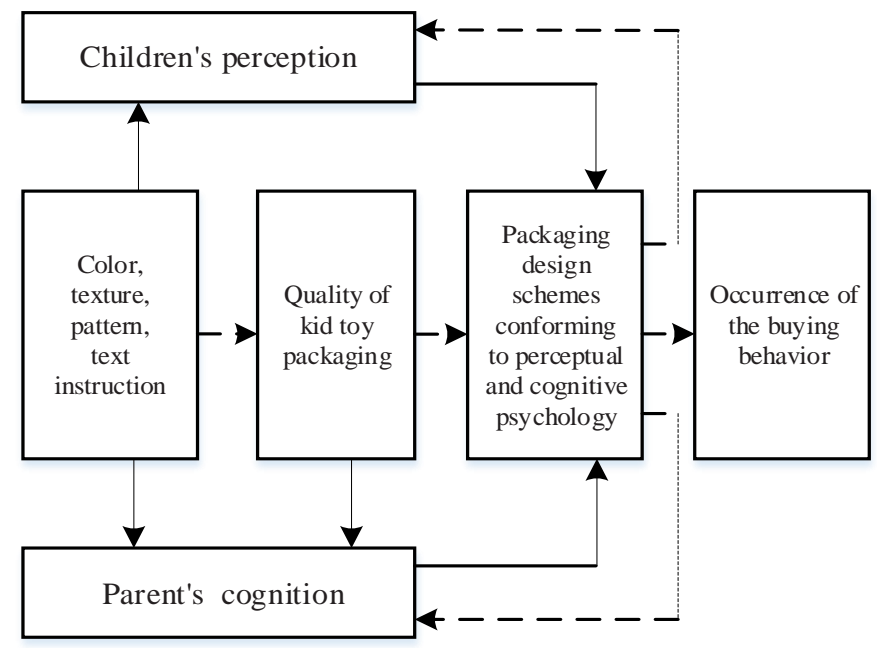

Fig.1. Conceptual model of kid toy packaging associated with the buying behavior

\section{PREPARATION FOR PREFERENCE TESTS}

\subsection{Test mode and testee}

Based on the conceptual model shown in Fig.1, the test methods is sensory physiology test for the real packages of kid toy packaging elements by predefined questionnaires; and testees are 100 children aged 3-11 who were randomly selected from the nursery and primary schools, and 100 parents whose ages distributed randomly. Children and parents were divided into two groups, the children acted as users and the parents acted as buyers. In the test, the real packages and the questionnaires are same.

\subsection{Test elements}

The questionnaire was designed entirely based on the kid toy packaging elements, namely, color, texture, pattern, and text instruction. The color includes contrasted or harmonious color, warm or cool tone, and high, medium or low intensity; the texture includes matted or glossy surface, flat or male and female surface, open-window or concealed packaging, photos or effect drawings; the pattern includes geometrical, natural and combined shape; and the text instruction includes professional instruction and popular instruction.

In order to get the details of the perceptual response of the users and the purchasers, the semantic differential method setting (Hsu etal. 2000) was used to set SEVEN levels of perceptual responses, namely Level -3 , Level -2 , Level -1, Level 0, Level 1, Level 2 and Level 3. Here "Level 0 " indicates that it is indifference, " Level 1 or Level $-1 "$ means prefer, " Level 2 or Level -2"means very prefer, "Level 3 or Level -3 " represents extremely prefer, respectively. Comparative objects are similar elements, such as cool tone and warm tone, openwindow packaging and concealed packaging, and so on. Details of the questionnaire are shown in Table1.

Because rational cognitive ability of children is not strong, the cognition of the children is physiological instinct, and the answers of the questionnaire for the children are simple and direct. However, the parents think questions deeply according to their own experience in real packaging test.

Table 1. Questionnaire and instruction based on the semantic differential method

\begin{tabular}{|c|c|c|}
\hline Test elements & $\begin{array}{c}\text { Level of perceptual } \\
\text { response }\end{array}$ & Description \\
\hline \multirow{2}{*}{$\begin{array}{c}\text { Comparative } \\
\text { object } 1\end{array}$} & 3 & Extremely prefer \\
\cline { 2 - 3 } & 2 & Very prefer \\
\hline & 1 & Prefer \\
\hline \multirow{2}{*}{$\begin{array}{c}\text { Comparative } \\
\text { object } 2\end{array}$} & -1 & Indifference \\
\cline { 2 - 3 } & -2 & Prefer \\
\cline { 2 - 3 } & -3 & Vxtremely prefer \\
\hline
\end{tabular}

\section{TEST PROCEDURE AND ANALYSIS}

\subsection{Questionnaire design}

For the kid toys with similar functions, slight differences in the package can change the purchasing decision. In order to attract the attention of children and parents, the kid toy packaging design must be optimized which means the package should meet the social cognition of parents and the physiological perception of children at the same time. In Tables 2, 3, Color 1, Color 2 and Color 3 denote contrasted colors vs. harmonious color, warm 
tone vs. cool tone, and high lightness vs. low lightness, respectively; Pattern 1, Pattern 2, Pattern 3 and Pattern 4 represent geometric shapes vs. natural shapes, geometric shapes vs. combinatorial shapes, natural shapes vs. combinatorial shapes, and photos vs. effect drawings, respectively; matted surface vs. glossy surface, flat surface vs. male or female surface, and open-window packaging vs. concealed packaging are expressed as Texture 1, Texture 2 and Texture 3, respectively; Text denotes popular instruction vs. specialized instruction. The sign " $\star$ " is the levels mark selected by testees.

Table 2. Children's preference test about the kid toy packaging elements

\begin{tabular}{|c|c|c|c|c|c|c|c|c|c|}
\hline \multirow{2}{*}{ Name } & \multirow{2}{*}{$\begin{array}{c}\text { Comparative } \\
\text { object } 1\end{array}$} & \multicolumn{7}{|c|}{ Level } & \multirow{2}{*}{$\begin{array}{c}\text { Comparative } \\
\text { object } 2\end{array}$} \\
\hline & & -3 & -2 & -1 & 0 & 1 & 2 & 3 & \\
\hline Color 1 & $\begin{array}{c}\text { Contrasted } \\
\text { colors }\end{array}$ & & & & $\star$ & & & & $\begin{array}{l}\text { Harmonious } \\
\text { colors }\end{array}$ \\
\hline Color 2 & Warm tone & & $\star$ & & & & & & Cool tone \\
\hline Color 3 & High lightness & & & & & & $\star$ & & Low lightness \\
\hline Pattern 1 & $\begin{array}{c}\text { Geometric } \\
\text { shapes }\end{array}$ & & & & & $\star$ & & & Natural shapes \\
\hline Pattern 2 & $\begin{array}{c}\text { Geometric } \\
\text { shapes }\end{array}$ & & & & $\star$ & & & & $\begin{array}{c}\text { Combinatorial } \\
\text { shapes }\end{array}$ \\
\hline Pattern 3 & Natural shapes & & & $\star$ & & & & & $\begin{array}{c}\text { Combinatorial } \\
\text { shapes }\end{array}$ \\
\hline Pattern 4 & Photos & & & $\star$ & & & & & Effect drawing \\
\hline Texture 1 & Matted surface & & & & & $\star$ & & & Glossy surface \\
\hline Texture 2 & Flat surface & & & & $\star$ & & & & $\begin{array}{c}\text { Male or female } \\
\text { surface }\end{array}$ \\
\hline Texture 3 & Open-window & & $\star$ & & & & & & Concealed \\
\hline Text & Popularization & & & $\star$ & & & & & Specialization \\
\hline
\end{tabular}

Table 3. Parents' preference test about the kid toy packaging elements

\begin{tabular}{|c|c|c|c|c|c|c|c|c|c|}
\hline \multirow{2}{*}{ Name } & \multirow{2}{*}{$\begin{array}{c}\text { Comparative } \\
\text { object } 1\end{array}$} & \multicolumn{7}{|c|}{ Level } & \multirow{2}{*}{$\begin{array}{c}\text { Comparative } \\
\text { object } 2\end{array}$} \\
\hline & & -3 & -2 & -1 & 0 & 1 & 2 & 3 & \\
\hline Color 1 & $\begin{array}{l}\text { Contrasted } \\
\text { colors }\end{array}$ & & & & $\star$ & & & & $\begin{array}{l}\text { Harmonious } \\
\text { colors }\end{array}$ \\
\hline Color 2 & Warm tone & & $\star$ & & & & & & Cool tone \\
\hline Color 3 & High lightness & & $\star$ & & & & & & Low lightness \\
\hline Pattern 1 & $\begin{array}{l}\text { Geometric } \\
\text { shapes }\end{array}$ & & & & & $\star$ & & & Natural shapes \\
\hline Pattern 2 & $\begin{array}{l}\text { Geometric } \\
\text { shapes }\end{array}$ & & & & $\star$ & & & & $\begin{array}{l}\text { Combinatorial } \\
\text { shapes }\end{array}$ \\
\hline Pattern 3 & $\begin{array}{l}\text { Natural } \\
\text { shapes }\end{array}$ & & & $\star$ & & & & & $\begin{array}{l}\text { Combinatorial } \\
\text { shapes }\end{array}$ \\
\hline Pattern 4 & Photos & & & $\star$ & & & & & Effect drawing \\
\hline Texture 1 & $\begin{array}{l}\text { Matted } \\
\text { surface }\end{array}$ & & & & & $\star$ & & & Glossy surface \\
\hline Texture 2 & Flat surface & & & & & $\star$ & & & $\begin{array}{l}\text { Male or female } \\
\text { surface }\end{array}$ \\
\hline Texture 3 & Open-window & & $\star$ & & & & & & Concealed \\
\hline Text & Popularization & & & $\star$ & & & & & Specialization \\
\hline
\end{tabular}

Note: Table 2 and Table 3, the statistical results are the weighted average of the test population and they are rounded.

\subsection{Analysis of data}

As can be seen from Table 2, the children very prefer warm colors and low lightness in color, and prefer the natural shape in pattern, and prefer the glossy surface, open-window packaging and photos in texture. Since children's cognitive capacity is limited, the children do not care about the text instruction. According to the statistical analysis, there is statistic error on color contrast. There are two different opinions on contrasted colors and harmonious color, some children like contrasting colors and other children prefer harmonious colors which is different from the weighted average results in Table 3. This kind of results has also been found in the kid toy packaging elements preference test for parents: some parents think harmonious colors are more important, more attractive, and more taste. Other color elements, texture elements, pattern elements, and text instruction are more in line with the actual situation. According to Tables 2, 3, it can be found that there are many differences in the visual perception of children and the social cognition of parents. In color intensity, children like low lightness, while parents prefer high lightness. For other kid toy packaging design elements, the preferences of children and parents are similar.

\section{DISCUSSION}

The optimization of kid toy packaging design is complex especially there are no uniform standard methods to follow; most of the designers design the packaging according to their individual feeling, which is lack of the investigation and analysis of the behaviours of the toy user and the toy purchaser. We have showed that the children's visual perception and the perceptual experience of parents can prompt the purchase of a kid toy. In order to improve the kid toy packaging design quality, the choice of the kid toy packaging design elements should follow the following principles:

(1) Colour. For the same kid toy, there should be two types of toys: one uses contrasted colours, and another uses harmonious colours. The purpose is to cater to the requirements of colour contrast of two distinct groups and help expand sales. The warm colours, namely red, yellow and orange; or a combination of these three colours, should be chosen. In colour lightness, the toy packaging design should choose two kinds of brightness on two principal panels: one side is used to attract children, and another side is used to attract parents. This method can coordinate the differences between the purchasers and the users.

(2) Pattern. Packaging graphic design using natural shape and geometry can meet the needs of both purchasers and users. For the combination 
wooden toys, such as building blocks toy, and some scenes toy, the recognition of parents and children is inconsistent, so the pattern of the combination of separate geometry should be used.

(3) Texture. Both children and parents are more like the convex surface which is smooth, thus the preferred toy packaging should choose the one which is convex smooth surface. It would be better that the package is open-window instead of closed since only the toy inside can attract the children other than the packaging itself. The open-window packaging can let the children have a look of the toy without removing the toy box. Moreover, the children and parents prefer photos instead of effect drawings, or diagrams; and it is better to use the picture of real products in the design process.

(4) Text instruction. The text instruction is not used to attract children, but to help parents quickly understand the function and precautions of toys, which can help parents make right buying decisions. For ordinary consumers, children's toys packing instructions should be concise and easy to be understood instead of being complicated jargon.

Based on these four principles, the packaging box of a kid food toy - "sugar painting - a Chinese traditional food toy" was designed to test the proposed principles. The reason of choosing "sugar painting" is that it is easy to get the materials and to produce; both children and parents are like buying it. On the packaging box, the "sugar painting" was drawn using golden colour which belongs to the warm colour; the background is red as the colour contrast, the brightness is designed as dim, the pattern is natural streamlined, the texture chosen as convex and smooth surface, open-window type, using the picture of the real "sugar painting", and using simple text to describe this product. According to our experiment, the test results in Tables 2 and 3 are consistent, although there are some deviations, mainly in the red colour contrast which is parents' preference. The reason of the deviation about the red colour is that the golden colour means the life is happy and sweet in China, and in Chinese festive the red colour is often used to heighten the festive atmosphere.

\section{CONCLUSIONS}

To set the kid toy packaging design mode and the evaluation criteria it is necessary to analyze colors, patterns, textures, text, and other basic elements of the packages based on the investigation of on the social cognition of parents and the physiological perception of children. The preference distributions of the children and the parents to the kid toy packaging elements were obtained and four kid toy packaging principles were proposed. One kid toy (sugar painting) package was designed and it validated the proposed results, which means that the optimal or sub-optimal kid toy packaging design can be achieved based on the proposed kid toy packaging design principles.

\section{ACKNOWLEDGMENTS}

This work was supported by the Tianjin Science Planning Project of Culture and Art of China under Grant No. D12022, and the Students' Platform for Innovation and Entrepreneurship Training Program of China under Grant No. 201410057045.

\section{REFERENCES}

[1] Liu, Y. \& Yang, M. 2011. Research on the Application of" Five Senses" in Packaging Design. Packaging Engineering 32(12):72-78.

[2] Tiwasing W. \& Sahachaisaeree N. 2012. Distinctive Design Perception: A Case of Toy Packaging Design Determining Children and Parents' Purchasing Decision. Procedia- Social and Behavioral Sciences 42(0): 391-398.

[3] Tiwasing, W. \& Sahachaisaeree, N. 2010. Conflicting purchasers' and users' appeal toward a design goal determining children and parent' purchasing decision: a case of toy packing design. Procedia-Social and Behavioral Sciences 5(0): 1357-1361.

[4] Flavell, J.H. etal. 1981. Young children's knowledge about visual perception: Further evidence for the Level 1Level 2 distinction. Developmental Psychology 17(1): 99103.

[5] Flavell, J.H. 1999. Cognitive development: Children's knowledge about the mind. Annual review of psychology 50(1): 21-45.

[6] Epstein, S. 1998. Cognitive-experiential self-theory in Advanced personality. Springer.

[7] Muth, C. \& Carbon, C.-C. 2013. The Aesthetic Aha: On the pleasure of having insights into Gestalt. Acta Psychologica 144(1): 25-30.

[8] Tracy, B. 2005. The Psychology of Selling: Increase Your Sales Faster and Easier Than You Ever Thought Possible. Thomas Nelson Inc.

[9] Budd, M. 1999. Aesthetic judgements, aesthetic principles and aesthetic properties. European journal of philosophy 7(3): 295-311.

[10] Hsu, S.H. Chuang, M.C. \& Chang, C.C. 2000. A semantic differential study of designers' and users' product form perception. International Journal of Industrial Ergonomics 25(4):375-391. 